\title{
Obstrução urinária por cisto ósseo aneurismático no osso peniano de um cão
}

\author{
Urinary obstruction secondary to an aneurysmal bone cyst in a penile bone of a dog
}

\author{
Tatiana Ojeda Verão ${ }^{\mathrm{I}}$ Alda Izabel de Souza ${ }^{\mathrm{I}{ }^{*}}$ Fabiana Mitie Matsubara Bergamo ${ }^{\mathrm{II}}$ \\ Antonio Marcelo Quintas Martins ${ }^{\mathrm{III}}$ Janecler Quieregati de Almeida Oliveira ${ }^{\mathrm{I}}$
}

\section{RESUMO}

Este relato trata de um cão atendido com sinal clínico de estrangúria, aumento de volume vesical e presença de massa indolor na região de osso peniano. A falha na sondagem uretral permitiu o diagnóstico de obstrução urinária. Ao exame radiográfico, observou-se massa radiopaca, de contorno regular, localizada na região da uretra peniana. Após remoção cirúrgica, o tecido foi submetido à análise histopatológica, que confirmou o diagnóstico de cisto aneurismático peniano - afecção ainda não relatada na espécie canina.

Palavras-chave: estrangúria, uretra, cão.

\section{ABSTRACT}

It is reported the case of a dog with strangury, increased bladder volume and presence of a painless mass in the region of penis bone. The failure of urethral probing allowed the diagnosis of urinary obstruction. A regular contour mass, moving and obstructing the urethra, was observed in the radiographic examination. After surgical removal, the tissue was submitted to histopathologic analysis, which confirmed the diagnosis of aneurismal cyst of the penis - yet unreported disease in dogs.

Key words: strangury, urethra, canine.

O cisto ósseo aneurismático é uma lesão benigna e não neoplásica que se desenvolve secundariamente às alterações hemodinâmicas da medula óssea, o que resulta em hemorragia, lise óssea e expansão subperiosteal com aumento de volume e dor local (PERNELL et. al., 1992).

Essa afecção é comum em seres humanos jovens e pode ocorrer em qualquer segmento do esqueleto, com maior frequência em ossos longos e corpos vertebrais (KRANSDORF \& SWEET, 1995). Tem incidência rara em animais e, quando ocorrem, desenvolvem-se principalmente nos ossos da pelve, costela e mandíbula (NOMURA \& SATO, 1997; BELKENAPet al., 1992; PERNELL et al., 1992; BILLER et al., 1987). O diagnóstico baseia-se na idade do paciente, na localização, nos sinais clínicos, na aparência radiológica e nos achados histopatológicos (KRANSDORF \& SWEET, 1995; PERNELL et al., 1992).

Em humanos, os tratamentos consistem de curetagem, excisão cirúrgica, enxerto ósseo, amputação, crioterapia e, mais raramente, radiação (KRANSDORF \& SWEET, 1995). Em cães, aplica-se com frequência a excisão cirúrgica (BRADY et al., 1998). O prognóstico está na dependência da progressão da doença, do osso afetado e da localização do cisto (SCHRADER et al., 1983).

Neste trabalho, é descrito o primeiro caso de cisto ósseo aneurismático no osso peniano de um

\footnotetext{
'Programa de Residência Médico-veterinária, Universidade Anhanguera (UNIDERP), Campo Grande, MS, Brasil.

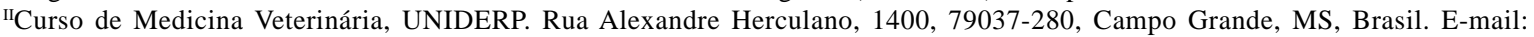
aldaizabel@hotmail.com.*Autor para correspondência. -

IIIHospital Veterinário, UNIDERP, Campo Grande, MS, Brasil.
} 
cão, associado à obstrução urinária. O animal com três anos de idade, da raça Pit Bull, foi encaminhado ao Hospital Veterinário da UNIDERP/Anhanguera com histórico de disúria desde filhote e desenvolvimento de estrangúria há três dias. Na palpação abdominal, observou-se repleção vesical e massa de consistência pétrea, arredondada, imóvel e indolor no osso peniano. Durante a sondagem vesical, não houve progressão da sonda na uretra peniana.

Os resultados da avaliação laboratorial hematológica e de bioquímica sérica mostraram-se normais. Na urinálise, identificou-se leucocitúria, hematúria e bacteriúria - achados indicativos de cistite.

No estudo radiográfico simples em posição látero-lateral direita, pode-se visualizar um aumento de volume na porção caudal do osso peniano, apresentando contorno regulare radiopaco, com leve incremento da radiopacidade no interior da cavidade. Na uretrografia, retrógrada, realizada após colocação de cateter urinário e infusão de $10 \mathrm{ml}$ de contraste positivo iodado (Pielograf ${ }^{\circledR} 76 \%$ ) diluído a $50 \%$ em solução fisiológica, observou-se desvio ventral e estreitamento da uretra, com obstrução total da passagem do contraste adjacente à massa, confirmando a compressão externa do lúmen uretral (Figura 1).

Na avaliação ultrassonográfica, pôde-se observar formação homogênea, oval, de contorno bem definido e hiperecóica, situada na região caudal do osso peniano, medindo aproximadamente $1,8 \mathrm{~cm}$ de diâmetro. A vesícula urinária foi visibilizada acentuadamente distendida com discreta sedimentação.

O diagnóstico diferencial para massa periuretral incluiu calcificação distrófica da glande do bulbo, hematoma calcificante, neoplasia mesenquimal do osso peniano e cisto ósseo.

Devido à persistente dificuldade de eliminação da urina e ao desconhecimento do diagnóstico definitivo, o animal foi submetido à exploração cirúrgica e biópsia excisional.

O paciente foi pré-medicado com diazepan e morfina e anestesiado com propofol e isufluorano, realizando-se administração de bupivacaína epidural. Após incisão de pele e tecido subcutâneo na região pré-escrotal, foram realizadas dissecação e excisão da massa óssea de contorno regular e cavidade cística, que circundava a uretra, preservando-a. Realizou-se a uretrostomia, incisando a uretra longitudinalmente e suturando a mucosa uretral à pele, com pontos isolados com fio de náilon 5-0.

A avaliação histopatológica identificou cisto envolto por uma parede formada por tecido ósseo, contendo septos de tamanhos variados preenchidos por sangue e separados entre si por tabiques de tecido conjuntivo, além de trabéculas de osteoide e pequena quantidade de célula gigante osteoclástica dispersa. Em algumas áreas, foi possível observar rimas contínuas de osteoblastos na periferia das trabérculas ósseas neoformadas (Figura 2).

Não foram identificadas evidências de tecido neoplásico ou processo infeccioso, confirmando assim a ocorrência do cisto ósseo aneurismático como causa do quadro obstrutivo urinário.

A etiopatogenia do cisto ósseo aneurismático ainda é desconhecida, mas acredita-se que alguns fatores como trauma, distúrbios hemodinâmicos da medula óssea, cisto ósseo simples e até neoplasias benignas ou malignas possam desencadear o seu desenvolvimento (BRADY et al., 1998; PERNELL et al., 1992).

Essa afecção tem sido descrita em cães, gatos, bovinos e equinos, principalmente em metáfises de ossos longos, assim como em vértebras, pelve e costelas, porém nenhum relato de envolvimento de osso peniano foi identificado na literatura (NOMURA \& SATO, 1997; BELKENAP et al., 1992; PERNELL et al., 1992; BILLER et al., 1987).

Cães jovens de raças grandes apresentam maior predisposição para o aparecimento dos cistos, e alguns autores acreditam que possam estar associados ao rápido crescimento do animal (BRADY et al., 1998; SCHRADER et al., 1983).

Os sinais clínicos mais comuns são dor, edema na região afetada, claudicação e, com menor

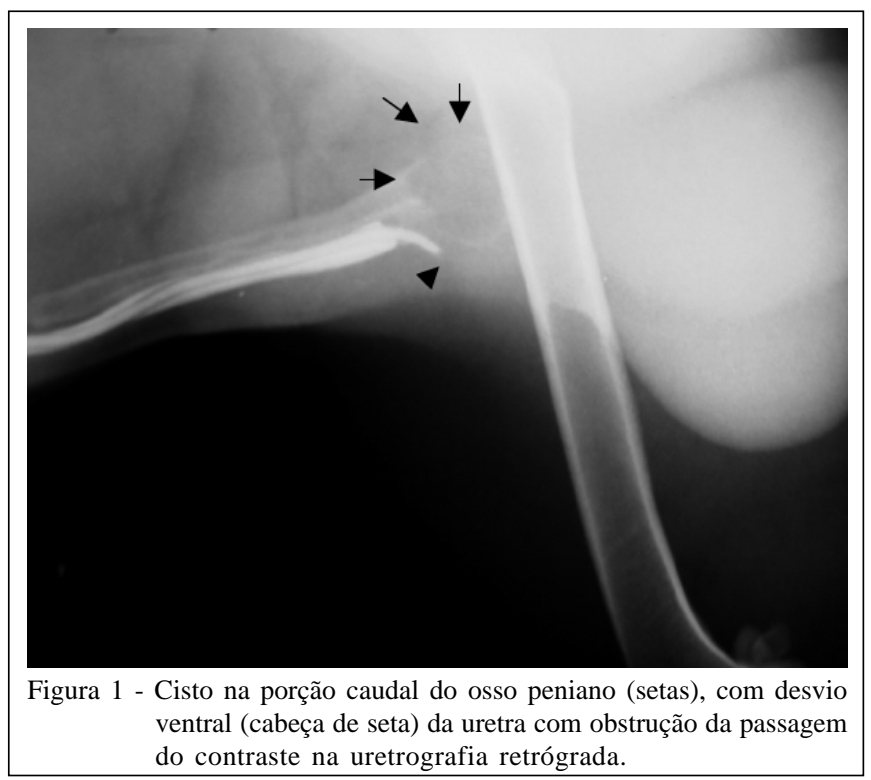




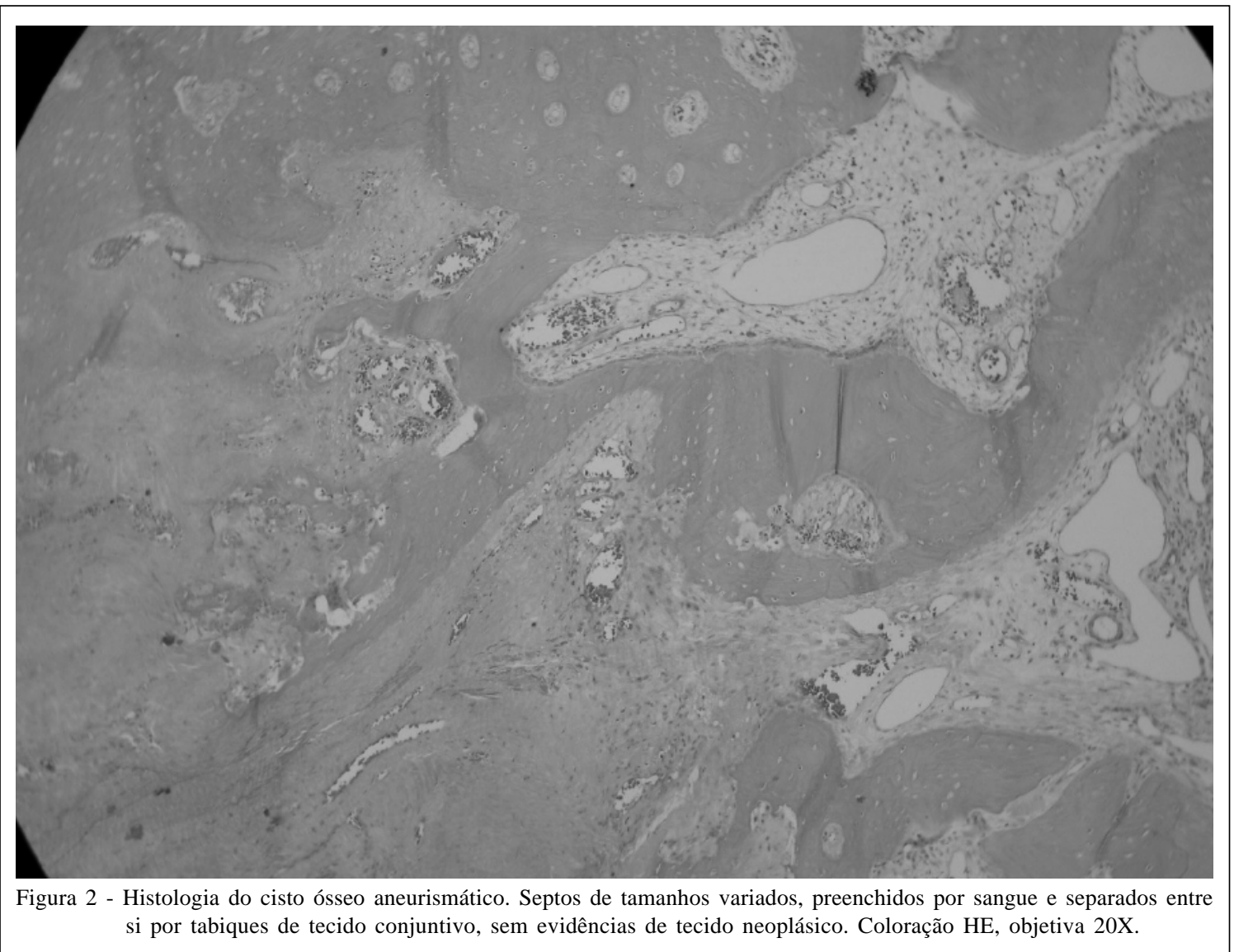

frequência, compressão de tecidos que cercam a região acometida, à semelhança do caso em questão, que desencadeou um quadro de estrangúria (NOMURA \& SATO, 1997; PERNELL et al., 1992; BILLER et al., 1987; SCHRADER et al., 1983; WALKER et al., 1975).

O diagnóstico diferencial deve incluir neoplasias, fraturas ou hematomas e baseia-se, além do exame físico, nos achados radiográficos e histopatológicos, nos quais se observam áreas expansivas de lise óssea, com perda completa da cortical, assim como a presença de trabéculas de tecido ósseo, fibroblastos, células gigantes multinucleadas, macrófagos e deposição de hemosiderina (MIRKOVIC et. al., 2004; BARNHART, 2002; PERNELL et al., 1992).

Os achados de diagnóstico por imagem e histopatológicos do presente relato assemelham-se à descrição de cistos ósseos aneurismáticos encontrados na literatura, porém é o primeiro caso com manifestação de estrangúria devido à localização no osso peniano. Nessa espécie, casos de obstrução uretral normalmente estão associados à formação de cálculos vesicais ou uretrais (MIRKOVIC et.al , 2004).
Devido à natureza destrutiva e desconhecida desse tipo de lesão óssea, o cisto ósseo aneurismático pode ser prematuramente diagnosticado como processo maligno, quando baseado somente em achados radiográficos e clínicos. Para evitar um diagnóstico equivocado, todas as lesões osteolíticas devem ser submetidas à biópsia antes do tratamento definitivo, principalmente quando as opções de tratamento são a amputação de membros e até a eutanásia (PERNELL et al., 1992).

No presente relato, a biópsia foi fator determinante na conclusão do caso, uma vez que a ausência de características neoplásicas isentou a necessidade de terapias adicionais.

Este caso é único em dois aspectos: 1) apresenta uma causa muito rara de obstrução urinária em cão macho; e 2) é o primeiro relato de cisto ósseo aneurismático em osso peniano canino.

\section{REFERÊNCIAS}

BARNHART, M.D. Malignant transformation of an aneurismal bone cyst in a dog. Veterinary Surgery, v.31, p.519-524, 
2002. Disponível em: <http://www3.interscience.wiley.com/ journal/118914794/abstract?CRETRY $=1 \&$ SRETRY $=0>$. Acesso em: 10 out. 2009. doi: 10.1053/jvet.2002.36014.

BELKENAP, E.B. et al. Aneurysmal bone cyst in a Holstein bull. Journal of the American Veterinary Medical Association, v.201, p.1413-1415, 1992.

BILLER, D.S. et. al. Aneurysmal bone cyst in a rib of a cat. Journal of the American Veterinary Medical Association, v.190, p.1193-1195, 1987.

BRADY, M.A. et. al. What is your diagnosis ? Journal of the American Veterinary Medical Association, v.213, p. 957958, 1998.

KRANSDORF, M.J.; SWEET, D.E. Aneurysmal bone cyst: concept, controversy, clinical presentation, and imaging. American Journal of Roentgenology, v.164, p.573-580, 1995. Disponível em: <http://www.ajronline.org/cgi/reprint/ 164/3/573>. Acesso em: 10 out. 2009. doi: 0361-803X195/ 1643-573.

MIRKOVIC, T.K. et. al. Urinary obstruction secondary to an ossifying fibroma of the os penis in a dog. Journal of the
American Animal Hospital Association, v.40, p.152-156, 2004. Disponível em: >http://www.jaaha.org/cgi/content/full/ 40/2/152>. Acesso em: 10 out. 2009.

NOMURA, K.; SATO, K. Pelvic aneurysmal bone cyst in a dog. Journal of Veterinary Medical Science, v.59, p.10271030, 1997. Disponível em: <http://www.ncbi.nlm.nih.gov/ pubmed/9409519>. Acesso em: 10 out. 2009.

PERNELL, R.T. et. al. Aneurysmal bone cyst in a six-monthold dog. Journal of the American Veterinary Medical Association, v.201, p.1897-1899, 1992. Disponível em: <http://www.ncbi.nlm.nih.gov/pubmed/1483911>. Acesso em: 10 out. 2009.

SCHRADER, S.C. et. al. Bone cysts in two dogs and a review of similar cystic bone lesions in the dog. Journal of the American Veterinary Medical Association, v.182, p.490-495, 1983. Disponível em: <http://www.ncbi.nlm.nih.gov/pubmed/ 6833086>. Acesso em: 08 out. 2009.

WALKER, M.A. et. al. Aneurysmal bone cyst in a cat. Journal of the American Veterinary Medical Association, v.167, p.933-944, 1975. Disponível em: <http://vdt.ugent.be/code/ showupload.php?id=109>. Acesso em: 10 out. 2009. 